\title{
Kapadokya Bölgesinin Drenaj Özellikleri
}

\section{Drainage Characteristics of the Cappadocia Region}

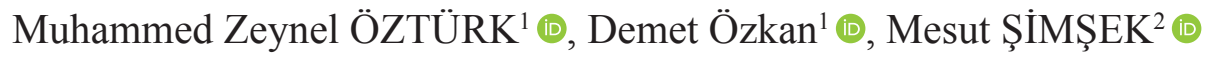 \\ ${ }^{1}$ Niğde Ömer Halisdemir Üniversitesi, Fen-Edebiyat Fakültesi, Coğrafya Bölümü, Niğde, Türkiye \\ ${ }^{2}$ Hatay Mustafa Kemal Üniversitesi, Fen-Edebiyat Fakültesi, Coğrafya Bölümü, Hatay, Türkiye
}

ORCID: M.Z.Ö. 0000-0002-9834-7680; D.Ö. 0000-0002-1141-7253; M.Ş. 0000-0002-4678-4336

\section{öz}

Kapadokya bölgesinde erozyonal süreçlere bağlı olarak ignimbirit ve tüfler üzerinde kırgıbayır topografyası yaygın olarak oluşmaktadır. Kırgıbayır topografyası içerisinde en dikkati çeken yer şekilleri ise peribacalarıdır ve bölge içerisinde peribacalarının oluşumunu denetleyen çok fazla sayıda faktör bulunmaktadır. İgnimbiritlerin tabakanlanma, sertlik ve gözeneklilik özellikleri, topografik eğim koşulları, ignimbiritler içerisindeki süreksizliklerin şekli, boyutu ve sıklığı, iklimsel özellikler, drenaj koşulları vb. unsurlar başta peribacaları olmak üzere kırgıbayır topografyasının gelişimi üzerinde etkilidir. Bu çalışmada alandaki kırgıbayır topografyası ve peribacası gelişimini denetleyen ana etmenlerden bir tanesi olan drenaj özellikleri 1/25.000 ölçekli topografya haritalarına göre incelenmiştir. Illk olarak topografya haritalarından tespit edilen tüm vadiler CBS ortamında sayısallaştırılmıştır. Ardından her bir vadiye dizin

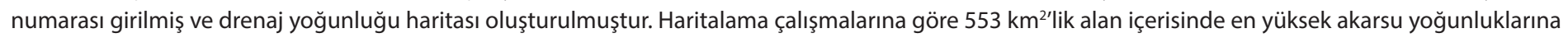
Göreme Milli Parkı sınırları içerisindeki ignimbirit ve tüflerde ulaşılmaktadır $\left(15.3 \mathrm{~km} / \mathrm{km}^{2}\right)$. Maximum akarsu yoğunluğunda en düşük değerler güney kesimdeki plato yüzeylerinde bazalt $\left(9 \mathrm{~km} / \mathrm{km}^{2}\right)$, andezit $\left(3.2 \mathrm{~km} / \mathrm{km}^{2}\right)$ ve dasitler $\left(4.2 \mathrm{~km} / \mathrm{km}^{2}\right)$ üzerinde görülür. Strahler yöntemine göre akarsu dizinlerinin \%53'ü 1. ve \%22.7'si 2. dizine aittir. Elde edilen bu sonuçlar Göreme Milli Parkını içine havzalarda en yüksek akarsu yoğunluğunun milli park içerisindeki ignimbirit ve tüfler üzerinde olduğunu göstermiştir.

Anahtar kelimeler: Drenaj yoğunluğu, erozyon, ignimbirit, Kapadokya

\section{ABSTRACT}

The morphology of the widespread badlands in the region of Cappadocia has mainly been the result of erosional processes on ignimbrite and tuff formations. Fairy chimneys are the most characteristic landforms of badlands morphology and many factors are responsible for the formation of these landforms in the region. Bedding, hardness and porosity of ignimbrites, shape, size and frequency of discontinuities in ignimbrites, slope, climate and drainage properties etc. of the area all significantly contribute to the development of badlands and fairy chimneys. In this study, drainage properties, which are one of the main controlling factors in this development, were investigated referencing $1 / 25.000$ scale topography maps. Firstly, all valley thalwegs were digitized using GIS. Subsequently, the Strahler order numbers of each stream were determined, and a drainage density map was created. Basing our results on maximum drainage densities, the highest drainage density $\left(15.3 \mathrm{~km} / \mathrm{km}^{2}\right)$ in the study area was identified in ignimbrite and tuffs in the Göreme National Park, whilst, the lowest drainage densities were located on plateau surfaces (basalt $\left(9 \mathrm{~km} / \mathrm{km}^{2}\right)$, dacite $\left(4.2 \mathrm{~km} / \mathrm{km}^{2}\right)$ and andesite $\left(3.2 \mathrm{~km} / \mathrm{km}^{2}\right)$ in the southern part of the study area. According to the Strahler order method, $53 \%$ and $22.7 \%$ of all streams belong to first and second orders, respectively. All these results show that drainage conditions on ignimbrite and tuffs are determinant factors in the formation of both badlands morphology and fairy chimneys.

Keywords: Drainage characteristics, erosion, ignimbrite, Cappadocia

Başvuru/Submitted: 14.01.2019 • Revizyon Talebi/Revision Requested: 31.01.2019 • Son Revizyon/Last Revision Received: 06.05 .2019 • Kabul/Accepted: 07.05.2019 - Online Yayın/Published Online: 17.05.2019 


\section{EXTENDED ABSTRACT}

The Cappadocia region located in the Central Anatolian Volcanic Province, has specific landforms formed as a result of physical and chemical weathering processes on Miocene-Pliocene ignimbrite and tuffs. Badlands morphology is the dominant landscape in this region. Fairy chimneys (capped earth pillars, erosion columns, chimney rocks) are typical landforms of badlands morphology and they are formed as a result of regression of valley slopes. However, many factors such as bedding, hardness and porosity properties of ignimbrites, shape, size and frequency of discontinuities in ignimbrites, slope, climate, vegetation, drainage properties of the area etc. are causes of the erosion and formation of fairy chimneys. Additionally, tectonic uplifts, climatic and river level oscillations during Quaternary also affected the appearance of the region. Alongside natural conditions, human activities of the past and present have also had a significant effect on the appearance of the region.

While drainage patterns and densities have been the main contributory factors in shaping this region they have not been studied in detail until today. Therefore, in this study, the spatial distribution of stream order and drainage density were investigated according to $1 / 25.000$ scale topography maps. Firstly, all the valley thalwegs in the drainage basin were identified from the topography maps and digitized using GIS software. Secondly, the Strahler order numbers of each stream were determined, and a drainage density map was created. Thirdly, three 1/100.000 scaled geology maps and data from three meteorology stations (Nevşehir, Avanos and Ürgüp) were used for the analysis of lithological units and climate as part of this study.

The study area is a volcanic plateau which has been highly eroded by rivers and deep narrow valleys. The area which includes drainage basins such as the Damsa Basin which flow from south to north, covers an area of $553 \mathrm{~km}^{2}$. The main drainage pattern in the area is the dendritic network. The elevation and slope of the area vary between 920 and 1949 meters, and $0^{\circ}$ and $69^{\circ}$, respectively. The badlands landscape and fairy chimney landforms are formed on Miocene-Pliocene ignimbrite and tuffs which frequently alternate with lacustrine and fluvial deposits. Eight types of ignimbrites were found in the Cappadocia region and fairy chimneys had developed on three of them (Kavak, Zelve and Cemilköy ignimbirites). These three units make up 53\% of the study area and their average slope is $8^{\circ}$.

Climate plays an important role in the development of the fairy chimneys. According to the Köppen climate classification, the climate type of the area is a cold semi-arid climate (type BSk) and accordingly, five months of the year are very dry. The annual average temperature and annual total precipitation of the area are $10^{\circ} \mathrm{C}$ and $367 \mathrm{~mm}$, respectively. The maximum temperature in summer months can reach $40^{\circ} \mathrm{C}$ and the minimum temperature in winter months can drop to $-24^{\circ} \mathrm{C}$. Maximum and minimum precipitations are observed in May $(52 \mathrm{~mm})$ and August $(4 \mathrm{~mm})$, respectively. Southern and northern winds are the prevailing winds in the area according to the Ürgüp Meteorology Station. Southern winds (SSE, S and SSW) account for 34\% of all winds.

According to the 1/25.000 scale topographic maps utilized in this study, a total of 21.973 stream orders were digitized with $53 \%$ and $23 \%$ of these are belong to first and second stream orders respectively. Ignimbrite and tuffs make up $66 \%$ of first and second order streams. The average drainage density is $6.4 \mathrm{~km} / \mathrm{km}^{2}$ with a drainage density of less than $9 \mathrm{~km} / \mathrm{km}^{2}$ across the majority of the study area $(84 \%)$. Minimum and maximum densities are observed in the southern and northern parts of the study area, respectively. The highest densities were identified in the Göreme National Park, in particular in the northeast part of Zelve and between Göreme, Çavuşin and Ortahisar. The maximum lithology densities were found in the ignimbrites and tuffs in the Göreme National Park (15.3 $\mathrm{km} / \mathrm{km}^{2}$ ). Furthermore, the lowest densities were identified on the plateau surface (composed of basalt, dacite and andesite) in the southern part of the study area. All these results show that drainage conditions are determinant factors in the formation of badlands morphology and fairy chimneys in the area of study. 


\section{GÍRIŞ}

İç Anadolu Volkanik Provensi içerisinde yer alan Kapadokya bölgesi fiziksel ve kimyasal ayrışma süreçlerine bağlı olarak, Miyo-Pliyosen ignimbirit ve tüfleri üzerinde ortaya çıkan ilginç jeomorfolojik unsurları içermesi bakımından ilgi çekici bir alandır (Topal ve Doyuran, 1998). Bölgede, vadi yamaçlarının genel olarak sağanak yağışlar nedeniyle oluşan sel karakterindeki akarsu vadileri (sel yarıntıları) ile bunlar arasındaki sırtlar şeklinde biçimlenmesiyle, kırgıbayır (badlands) topografyası olarak adlandırılan engebeli bir topografya meydana gelir. Yüksek eğimli yamaçlardan oluşan kırgıbayır topografyası zayıf vejetasyon örtüsüne, yüksek drenaj yoğunluğuna ve yüksek erozyon oranına sahiptir (Howard, 1994). Kırgıbayır topografyası genel olarak kurak ve yarı-kurak alanlara özgü jeomorfolojik birimler olarak tanımlanmışsa da (Erinç, 2000), yarı-nemli iklim koşullarında da s1k s1k rastlanılmaktadır (Howard, 1994; Tanrıkulu, 2016). İklimsel özelliklerin uygunluğu, açısından özellikle Akdeniz çevresindeki ülkelerde kırgıbayır topografyası yaygın olarak oluşmaktadır (Nadal-Romero vd., 2011).

Kırgıbayır topografyası içerisinde erozyonun şiddetine bağlı olarak farklı yer şekilleri oluşur. $\mathrm{Bu}$ yer şekillerinin en karakteristiği, pediment düzlükleri arasındaki vadi yamaçlarında, yamaçların gerilemesiyle birlikte oluşan peribacalarıdır (Sür, 1966; Arık, 1981; Emre ve Güner, 1988).Peribacaları (capped earth pillars, erosion columns, chimney rocks, fairy chimneys) genel olarak Kavak, Zelve ve Cemilköy ignimbiritleri üzerinde gelişme gösterir (Sayın, 2008). Ancak bu ignimbiritler üzerinde erozyonun alansal olarak farklılık göstermesinden dolay1 peribacası gelişimi her yerde aynı şekilde gerçekleşmemektedir. İgnimbiritler üzerinde erozyonun alansal dağılışı çok fazla sayıda faktör tarafından denetlendiğinden dolayı erozyon şiddeti her yerde aynı değildir (Erşen, 2010; Tanrıkulu, 2016). Genel olarak ignimbiritlerde erozyon hız1 $0.58-28 \mathrm{~cm} /$ bin y1l, tüflerde ise 0.03 $2.25 \mathrm{~mm} / \mathrm{y} 1 \mathrm{l}$ oranında değişmekle birlikte (Erguler, 2009; Sarıkaya vd., 2015), Yılmaz vd., (2012) tarafindan 15 aylık gözlem periyodunda ayrışma hızını $1.19 \mathrm{~mm}$ olarak bulunmuştur.

İgnimbirit ve tüfler üzerindeki erozyon şiddetini, dolayısıyla alandaki peribacası gelişimini belirleyen başlıca faktörler aşağıdaki şekilde özetlenebilir. İgnimbiritlerin tabakalanma özellikleri, özellikle ignimbiritler içerisindeki katmanların kalınlığı ve sertliği, peribacalarının morfolojik görünümlerini etkileyen en önemli faktörlerden bir tanesidir (Aydar vd., 2013). Özellikle şapkalı peribacalarının üst kesimleri pekleşmiş ve daha sert birimden oluşurken, alt kesimleri (boyun ve gövdeleri) pekleşmemiş ve daha yumuşak birimlerden meydana gelmektedir.
Bundan dolayı şapka yapılarının korunabildiği alanlarda erozyonun şiddeti daha az iken, şapkaların ortadan kalktığı yerlerde erozyon şiddeti daha fazladır (Çiner vd., 2013). Topografik koşullar açısından erozyon ve peribacası oluşumunu kontrol eden en önemli faktör eğim koșullarıdır. Peribacalarının oluşumu genel olarak düşük eğimli yamaçlar üzerinde başlamaktadır (Sarıkaya vd., 2015). Kavak, Zelve ve Cemilköy ignimbiritleri üzerinde peribacalarının oluştukları alanda eğim değerleri sırasıyla $4^{\circ}-17^{\circ}, 2^{\circ}-13^{\circ}$ ve $8^{\circ}-23^{\circ}$ arasında değissmektedir. Peribacasının oluştuğu alanın eğim değerleri ise pekleşmenin derecesine ve ignimbiritin kalınlığına göre değişmektedir (Sayın, 2008). Uygun eğim koşulları altında peribacalarının oluşumunda genel olarak sel karakterindeki akarsular (Aydar vd. 2013) etkili olmakla birlikte bazı çalışmalar rüzgârında peribacası oluşumuna birkaç farklı şekilde katkı sağladığını belirtmişlerdir. Yalçınlar (1969), Ozaner ve Atiker (2006) şiddetli rüzgârların taşıdığ 1 küçük tanelerin sürtünmesiyle peribacası oluşumuna katkı sağladığını, Giovanni (1971) ise rüzgâr etkisinin peribacalarının boyun kısmını oluşturan tüflerde daha fazla etkili olduğunu belirtmiştir. Giovanni (1971) aynı zamanda bu zonun altındaki gövde kısmında yağış, donma-çözülme ve yağmur suyu ile yıkanmanın etkili olduğunu belirtmiştir. Peribacaları genel olarak bitki örtüsünün olmadığ ya da çok az olduğu yüzeyler üzerinde geliştiğinden dolayı yağış miktarı ve yağışın şiddeti de erozyonun şiddeti ve sel yarıntılarının oluşumu üzerinde önemli etkiye sahiptir (Emre, 1985; Erinç, 2000; Sayın, 2008; Tanrıkulu, 2016). İklimsel parametreler (yağış, donma-çözülme ve rüzgâr) alandaki ana ayrıştırıcı unsurlar olmakla birlikte alan içerisinde bu parametrelerin etkisini azaltan bazı etmenler bulunmaktadır. Bunlardan en önemlileri liken örtüsü ile oksidasyon kabuklarıdır. Peribacalarının gövdelerini kaplayan liken örtüsü özellikle suyun etkisini ve dolayısıyla erozyonun şiddetini azalmaktadır (GarciaValles vd., 2013). Kopar (2010) peribacalarının üstlerinde oluşan oksidasyon kabuklarının peribacalarını dış etmenlerden koruyan bir zırh görevi gördüğünü ancak bu kabuk oluşumunun her yerde farklı seviyelerde olmasından dolayı her yerde bu etkinin görülmediğini belirtmiştir. Baba vd. (2015) ise peribacası oluşumunda çimento malzemesinin $\left(\mathrm{Fe}_{2} \mathrm{O}_{3}\right.$ ve $\left.\mathrm{CaO}\right)$ önemli rol oynadığını ve kimyasal bileşimin peribacalarının gelişimi, boyutunda ve sağlamlığında etkili olduğunu açıklamışlardır.

Yapısal açıdan kırgıbayır ve peribacalarının oluşumunu denetleyen en önemli unsur termal stresten kaynaklanan çatlak sistemleridir (süreksizlikler). Topal ve Doyuran (1997) tarafından yapılan ölçümlere göre alanda süreksizlerin doğrultusunda $\mathrm{N} 78^{\circ} \mathrm{E}$ ve $\mathrm{N} 85-90^{\circ} \mathrm{W}$ yönleri egemendir. Süreksizliklerin arasındaki mesafe 0,1 metre ile 20 metre arasında değişmekte ve devamlılıkları 10 metreyi bulmaktadır (Topal ve Doyuran, 
1997). Süreksizliklerin aralığı ve sıklığı aynı zamanda peribacalarının saha içerisindeki dağılımını, yoğunluklarını ve dirençlerini denetlenmektedir (Emre ve Güner, 1985; Topal, 1995; Topal ve Doyuran, 1997). Süreksizlikler boyunca hareket eden su kütlesi (yağmur suyu) hem aşağı doğru hareketi esnasında ayrışmış malzemeyi taşır, hem de kütle içerisindeki fiziksel ve kimyasal ayrışmayı kolaylaştırır. Soğuk dönemlerde ise bu süreksizlikler içerisinde donan suyun neden olduğu basınç, erozyonu şiddetlendirmektedir (Bilgili, 2018).

Litolojik, petrografik ve yapısal özelliklerinin yanısıra Kuvaterner sirasında meydana gelen tektonik yükselimler, iklimsel salınımlar ve Kızılırmak'ın seviyesinde meydana gelen salınımlar, alanın ve dolayısıyla peribacalarının gelişimi ve bölgenin günümüzdeki görünümünün oluşması üzerinde etkili olmuşlardır (Sür, 1966; Arık, 1981; Emre ve Güner, 1985, 1988; Doğan, 2011; Çiner vd., 2015; Koçyiğit ve Doğan, 2016; Doğan vd., 2018). Damsa Çayı tarafından derin vadiler şeklinde yarılan çalışma alanı son 5-2 milyon yılda 0.06-0.08 mm/yıl gömülme oranına sahiptir (Doğan, 2011; Aydar vd., 2013; Çiner vd., 2015). Yukarıda bahsedilen doğal koşulların yanı sıra alanın uzun zamandır yerleşim birimi olarak kullanılması ve günümüzde yoğun bir turistik merkez olmasından dolayı, beşeri koşullarda alandaki erozyon miktarı üzerinde önemli bir etkiye sahiptir (Güngör, 2016; Bilgili, 2018; Çiner ve Aydar, 2019).

Yukarıda kısaca açıklandığı gibi alandaki erozyonun şiddeti, alansal dağılışı ile peribacalarının gelişimlerinde, dağılımlarında ve geometrilerinde, başka bir ifade ile alandaki erozyonal süreçleri denetleyen birçok faktör bulunmaktadır. Genel olarak erozyon aktivitesinin en fazla olduğu alanlarda meydana gelen peribacaları, aktivitenin şiddetine ve şekline göre farklı yoğunluk ve biçimlerde gelişme göstermişlerdir (Görüm vd., 2007; Sayın, 2008; Polat ve Güney, 2013). Alandaki peribacası oluşumları ile ilgili çalışmalar 1940’l1 yıllardan beri (Tromp, 1942; Chaput, 1947) günümüze kadar devam etmiş olmakla birlikte, peribacalarının ve alanın günümüzdeki görünümünün oluşumunda ana ayrışma etkenlerden bir tanesi olan drenaj özellikleri tam olarak açıklanmamıştır. $\mathrm{Bu}$ eksiklikten dolayı çalışmada Göreme Milli Parkını (Avanos, Ürgüp, Ortahisar, Uçhisar, Zelve, Göreme) içerisine alan havzalar içerisindeki drenaj özellikleri 1/25.000 ölçekli topografya haritalarına göre incelenmiştir.

\section{VERİ VE YÖNTEM}

Çalışma alanı Göreme Milli Parkı sınırlarını içerisine alan akarsu havzalarına göre belirlenmiştir. Yapılan haritalama çalışmasına göre 7 adet 1/25.000'lik topografya haritası içerisinde kalan $553 \mathrm{~km}^{2}$ 'lik alandaki tüm vadi talvegleri Coğrafi Bilgi Sistemleri (CBS) ortamında sayısallaştırılmıştır. Sayısallaştırma işlemlerinin ardından tüm vadiler Strahler yöntemine (Strahler, 1957) göre numaralandırılmış ve alansal hesaplamaları yapılmıştır. Strahler yönteminde, yan kol olmayan fakat küçükte olsa akışa sahip bir segment 1. dizin olarak isimlendirilmiştir. İki tane 1. dizin birleşince 2. dizini, iki tane 2. dizin birleşince 3 . dizini oluşturur. Bu sistemde daha küçük bir dizin kendisinden büyük bir dizinle birleşince dizin değerinde bir artış olmaz. Ancak iki eşdeğer dizin birleşirse dizin sıralamasında bir artış olabilmektedir. Böylece Strahler yönteminde küçük dizinlerin (kolların) etkisi gözardı edilmiştir (Özdemir, 2011).

Havzanın akarsular tarafından parçalanma derecesini gösteren drenaj yoğunluğu $\left(\mathrm{km} / \mathrm{km}^{2}\right)$ belirli bir bölgede akarsuların toplam uzunluğunun $(\mathrm{km})$ o bölgenin $\mathrm{km}^{2}$ cinsinden alan değerine bölünmesiyle elde edilir (Turoğlu, 1997). Drenaj yoğunlukları alanın yapısal özellikleri, rölyefi, jeolojisi, iklimi, toprak yapısı, bitki örtüsü özellikleri gibi yüzeysel akışı kontrol eden faktörlere bağlı olarak şekillenmektedir (Tucker vd., 2001; Özdemir, 2006; Utlu ve Özdemir, 2018). Bu özelliğinden dolayı drenaj yoğunluğu erozyon özellikleri, tektonik yükselim, jeomorfolojik gelişim konularında önemli bilgiler sağlayan bir veridir (Tucker vd., 2001). Topografya haritalarından çizilen vadilerin yoğunluk haritası oluşturabilmek amacıyla karelaj yöntemi kullanılmış ve $\mathrm{km}^{2}$ 'deki toplam akarsu uzunluğu tespit edilmiştir. Ardından tespit edilen değerler CBS ortamında enterpolasyon yöntemi kullanılarak alansal dağılış haritası oluşturulmuştur.

Alana ait 1/25.000 ölçekli topografya haritalarından alana ait sayısal yükseklik modeli ve eğim haritası oluşturularak alansal hesaplamaları yapılmıştır. Alanın litolojik birimleri için Atabey (1989 a,b) ve Dönmez vd. (2015) tarafindan hazırlanan 1/100.000 ölçekli jeoloji haritalarından yararlanılmıştır.

İklimsel özelliklerin yorumlanmasında alanın kuzey kesiminde bulunan Avanos meteoroloji istasyonu, merkezinde yer alan Ürgüp meteoroloji istasyonu ve batısında yer alan Nevşehir meteoroloji istasyonlarına ait ortalama bültenlerden yararlanılmıştır.

\section{1. Çalışma Alanı}

\subsection{Yükselti ve eğim koşulları}

Çalışma alanı Kapadokya Bölgesi, Kapadokya Volkanik Alanı, Kapadokya Volkanik Kompleksi gibi çeşitli şekillerde adlandırılan bölgenin kuzey kesiminde bulunur. Kapadokya Bölgesi’nin 
doğusu KD-GB uzanımlı Orta Anadolu (Ecemiş) Fay Zonu, batısı KB-GD uzanımlı Tuzgölü Fay Zonu, kuzeyi D-B uzanımlı Orta Kızılırmak Fay Zonu (Avanos Fayı) ile sınırlandırılmış olup alan içerisinde K-G uzanımlı Derinkuyu Fayı, KKB-GGD uzanımlı Göllüdağ Fayı ve KD-GB uzanımlı Niğde Fayı yer almaktadır (Şener, 2015; Koçyiğit ve Doğan, 2016; Şener vd., 2017).

Göreme Milli Parkı'nı içerisine alan ve 553 km²'lik alanı kaplayan çalışma sahasının büyük çoğunluğu mevsimsel karakterdeki çok fazla sayıda irili ufaklı akarsu tarafından Kızılırmak'a drene edilmektedir (Şekil 1a,b). Kızılırmak ve Ecemiş fay zonlarının kesişiminde yer alan ve dendritik drenaj ağına sahip Damsa Çayı Havzası alandaki en önemli havzadır. Güneyden kuzeye doğru akarak Kızılırmak’a bağlanan ve çalışma alanının büyük bölümünü oluşturan bu havzadaki drenaj ağının gelişmesinde yapının önemli bir etkisi olmuştur (Altın ve Toprak, 2007). Damsa Çayı tarafından derin vadiler şeklinde yarılan çalışma alanı son 5-2 milyon yılda 0.06-0.08 mm/yıl gömülme oranına sahiptir (Doğan, 2011; Aydar vd., 2013; Çiner vd., 2015).

Alanın ortalama yüksekliği 1325 metre olup, yükseklik güneyden kuzeye doğru azalmaktadır. Alandaki en yüksek nokta 1949 metre ile Hodul Dağı iken, en alçak alanı kuzeydeki Avanos civarıdır (920 m; Şekil 1c). Çalışma alanında en geniş yükselti
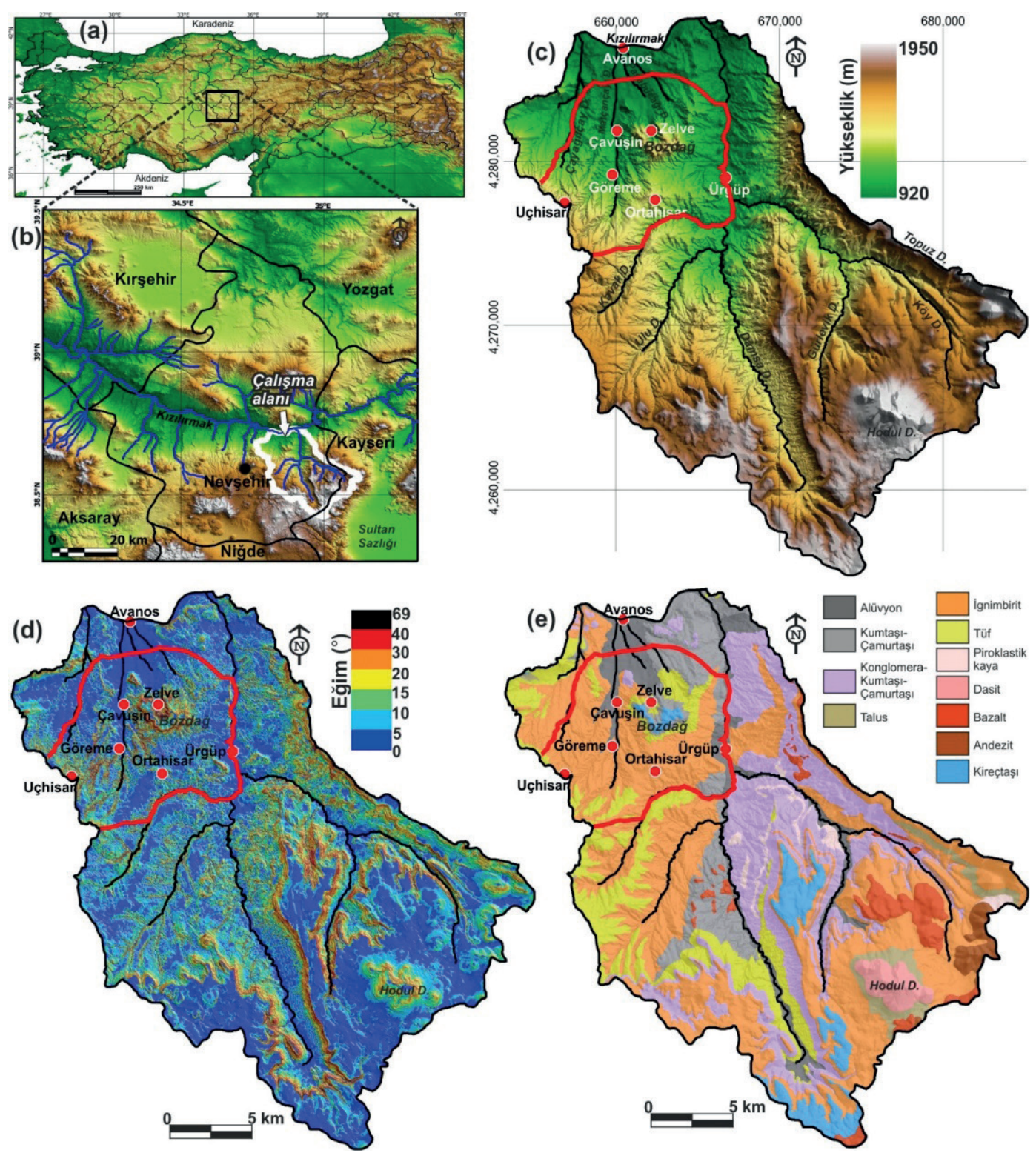

Şekil 1: (a, b) Çalışma alanının lokasyonu, (c) çalışma alanına ait sayısal yükseklik modeli, (d) eğim ve (e) jeoloji haritaları (Atabey, 1989a,b, Dönmez vd., 20015'den düzenlenerek; c,d ve e'deki kırmızı alanlar Göreme Milli Parkı sınırını göstermektedir).

Figure 1: ( $a, b)$ Location of the study area, (c) digital elevation model, (d) slope and (e) lithology maps (arranged from Atabey, 1989a,b, Dönmez vd., 20015) of the study area (red lines in c,d and e show boundary of Göreme National Park) 
aralığı 1500-1600 metreleri arasıdır (\%23). Bu yükselti aralı̆̆1 özellikle alanın güneyindeki yüksek platolar üzerinde geniş alan kaplamaktadır. 1600 metrenin üstündeki alanlar alanın sadece \%5'lik kesimini oluşturmaktadır.

Akarsular tarafından yarılmış volkanik bir plato görünümünde olan çalışma alanında eğim koşulları $0-69^{\circ}$ arasında değiş̧mektedir (Şekil 1d). En yükssek eğimli alanlar başta Damsa Çayı olmak üzere vadilerin üst kısımlarında ve Göreme Milli Parkı merkezindeki Bozdağ çevresinde görülür (Şekil 1d, 2). En düşük eğim koşulları ise alanın güneyindeki yüksek platolar üzerinde ve kuzeyindeki vadi tabanlarında görülür. 0-10 arasındaki düz ve hafif eğimli alanlar \%65'lik bir alan kaplarken eğimin $30^{\circ}$ 'nin üstündeki alanlar sadece \%2.79'luk bir kesimini oluşturmaktadır. Litolojik birimlere göre ortalama eğim değerleri Hodul Dağı'nı oluşturan dasitlerde $14.5^{\circ}$ ve Damsa Çayı'nın yamaçlarını oluşturan konglomera-kumtaş1-kiltaşı ardalanması üzerinde ise $13.6^{\circ}$ dir. Peribacalarının üzerinde geliştiği ignimbirit ve tüfler üzerindeki ortalama eğim koşulları ise 8.4$8.6^{\circ}$ değerleri arasında değişmektedir.

\subsection{2. İklim}

Kırgıbayır topografyası ve peribacalarının oluşumunda yağış ve donma-çözülme gibi iklimsel parametreler büyük etkiye sahiptir (Süre, 1972; Emre ve Güner, 1985; Y1lmaz vd., 2012). Özellikle ilkbahar ve yaz mevsimindeki kısa süreli sağanak yağışlar (orajlar) yüksek miktarda yüzeysel akışa neden olduğu için kırgıbayır topografyasının şekillenmesinde önemli rol oynar (Phillips, 1998). Avanos, Ürgüp ve Nevşehir istasyonlarının ortalamalarına göre alanda yıllık ortalama toplam yağış 367 mm'dir. Ekim-Haziran döneminde aylık toplam yağış değerleri 30 mm'nin üstündedir. En yüksek yağış değerleri Nisan $(50 \mathrm{~mm})$ ve Mayıs $(53 \mathrm{~mm})$ aylarında görüldüğü alanda en düşük yağışlar Ağustos'ta görülür $(4 \mathrm{~mm})$. İstasyon verilerine göre alanda 12 günü Nisan-Haziran döneminde olmak üzere yıllık toplam 17 gün oraj yağışı gerçekleşmektedir. Üç istasyonun ortalamasına göre yıllık ortalama sicaklık $10.9^{\circ} \mathrm{C}$ 'dir. Ortama sicaklıklarda en yüksek değerlere $22.4^{\circ} \mathrm{C}$ ve $22^{\circ} \mathrm{C}$ ile Temmuz ve Ağustos aylarında ulaşılır (Şekil 3). Ancak maksimum değerler dikkate alındığında bu aylardaki sıcaklıklar $40^{\circ} \mathrm{C}$ 'nin üstüne çıkmaktadır. En soğuk ay
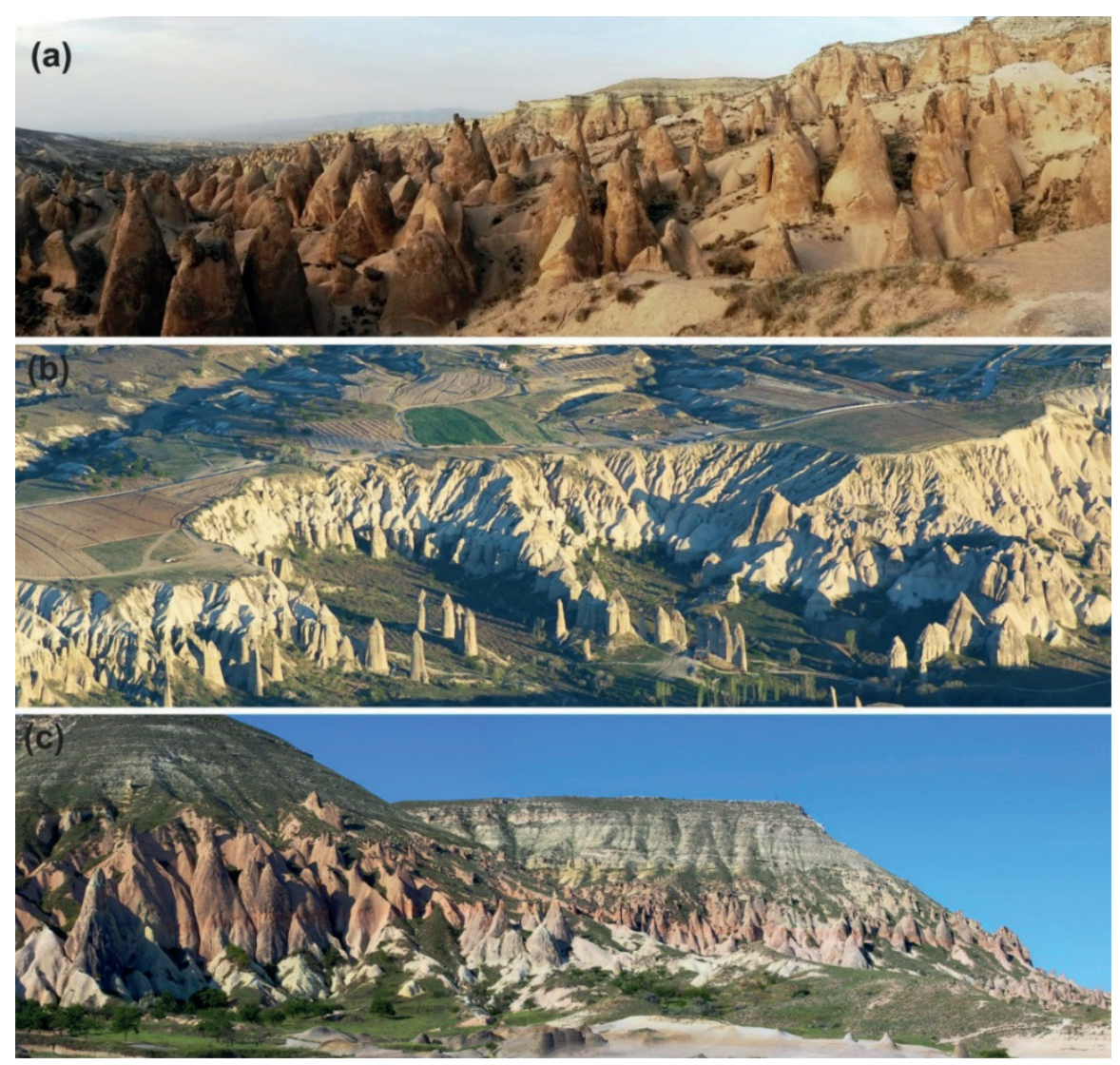

Şekil 2: Çalışma alanındaki farklı eğim koşullarına örnekler (a) peribacalarının gelişimine uygun düşük eğimli alanlar, (b) vadilerin üst kısımlarında sel karakterli akarsuların etkisiyle oluşan yüksek eğimli alanlar ve (c) Milli park içerisindeki Bozdağ çevresindeki yüksek eğimli alanlar.

Figure 2: Examples to different slope conditions in the area; (a) suitable gently slope areas for fairy chimneys, (b) steep slopes shaped by gullies in the upper part of the valleys, (c) steep slopes around Bozdağ located in national park. 


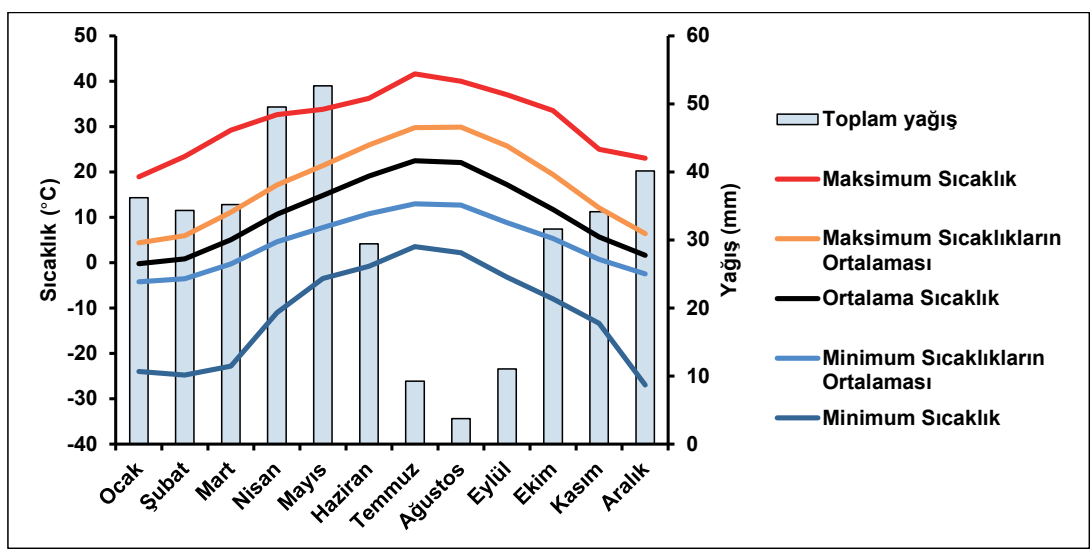

Şekil 3: Üç meteoroloji istasyonuna ait ortalama sıcaklık ve yağış değerlerinin aylık değişimi.

Figure 3: Change of monthly average temperature and precipitation of the three meteorology stations.

olan Ocak'ta ortalama sıcaklıklar $-0.2^{\circ} \mathrm{C}$ iken minimum değerler $-24^{\circ} \mathrm{C}^{\prime}$ ye kadar düşmektedir (Şekil 3). Maksimum ve minimum değerlere göre Ekim-Nisan dönemlerinde donma-çözülme görülme ihtimali bulunmaktadır ve bu dönemde minimum sıcaklığın $-0.1^{\circ} \mathrm{C}$ 'nin altında olduğu günler sayısına göre ortalama 99 gün donma olayı gerçekleşmektedir. Sıcaklık değerlerinin yüksek, yağış değerlerinin düşük olduğu çalışma alanı KöppenGeiger iklim sınıflandırmasına göre Bsk harfleri ile temsil edilen "yarı-kurak soğuk step iklimi" içerisinde yer alır (Öztürk vd., 2017). Thornthwaite iklim sınıflandırmasına göre çalışma alanı C1B'1db'3 ile sembolize edilen "kurak-yarınemli, birinci mesotermal, su fazlası yıl boyunca çok az ya da hiç olmayan, sıcaklık etkinliğinin yaz konsantrasyonu üçüncü mesotermal iklim" ile tanımlanır (Türkeş, 2005). Kuraklığın oldukça belirgin olduğu alanda yılda 5 ay kurak geçmektedir (Çiçek, 1995).

Yılda 10 gün firtınanın (rüzgar hızı $\geq 17.2 \mathrm{~m} / \mathrm{s}$ ) yaşandığ 1 alanda yıllık toplam kuvvetli gün sayısı (rüzgar hızı 10.8-17.1 m/s) 63'tür. Alandaki en hızlı rüzgârlar GD ve GB yönlerinden esmekte olup rüzgâr hızı $37 \mathrm{~m} / \mathrm{s}$ hıza kadar çıkabilmektedir. Hâkim rüzgâr yönü istasyonun bulunduğu alanın morfolojisinden etkilendiği için hâkim rüzgâr yönü özellikleri açıklanırken çalışma alanının merkezinde bulunan Ürgüp meteoroloji istasyonu verilerden yararlanılmıştır. Ürgüp istasyonunun verilerine göre alanda, Damsa Vadisi'nin uzanımına paralel olarak kuzey ve güney sektörlü rüzgârlar hâkimdir. Güney sektörlü (GGD, G ve GGB yönlerinden esen) rüzgârlar tüm esme sayılarının \%34'ünü, kuzey sektörlü rüzgârlar (KKB, K ve KKD yönlerinden esen) rüzgârlar tüm esme sayılarının \%25'ini oluşturmaktadır.

\section{LITOLOJi}

Çalışma sahası içerisinde kırgıbayır topografyası ve peribacaları çok düşük birim ağırlığına, yüksek gözenekliliğe sahip Miyo-
Pliyosen ignimbirit ve tüfler üzerinde gelişme göstermiştir (Pasquare, 1968; Topal ve Doyuran, 1998; Şekil 1e). Erciyes, Hasandağı ve Acıgöl volkanlarından kaynaklanan bu ignimbirit ve tüfler gölsel sedimentlerle ardalanmalı olarak birikmiştir. K/Ar yöntemiyle yapılan tarihlendirmelere göre ignimbirit ve tüfler 142.4 milyon yılları arasında sekiz farklı dönemde oluşmuştur. $\mathrm{Bu}$ birimler alttan üste doğru sırasıyla Kavak, Zelve, Sarımaden Tepe, Cemilköy, Tahar, Gördeles, Kızılkaya, Valibaba Tepe ignimbiritleridir. $\mathrm{Bu}$ dönemlerin yanı sıra 8.4-2.2 milyon yılları arasında üç farklı dönemde lav akışı (bazalt ve andezit) (Erciyes, Topuzdağ ve Damsa lavları) gerçekleşmiştir (Innocenti vd., 1975; Temel, 1992; Le Pennec vd., 2005).

Alanda sekiz farklı döneme ait ignimbirit oluşumu gözlenmekle birlikte, peribacası oluşumları ve bandlands topografyası özellikle Kavak, Zelve, Cemilköy ignimbiritleri üzerinde gelişme göstermiştir. Aydan ve Ulusay (2003) ve Sayın (2008) çalışmalarına göre peribacalarının üzerinde geliştiği ignimbiritlerde gözeneklilik oran $\% 38$ 'e kadar yükselmektedir. Çalışma alanındaki en geniş yayılıma sahip olan ve üzerinde peribacaları ile bandlands topografyasının yaygın olarak geliştiği Kavak ignimbiriti ofiyolitik temel üzerinde uyumsuz olarak bulunur ve kuzeye doğru 3-7 ${ }^{\circ}$ lik eğime sahiptir. Pekleşmemiş şekilde, krem ve pembemsi renklerde bulunan bu birim tüf ve süngertaşı katmanları ile birlikte flüvyal ve gölsel sedimentler de içerir (Sayın, 2008). İgnimbiritin yaşı $\mathrm{K} / \mathrm{Ar}$ yöntemine göre 8.6 my (Innocenti vd., 1975), 11.2 my (Temel, 1992), 9.2-6.9 my (MuesSchumacher ve Schumacher, 1996) ve 14-9 my (Le Pennec vd., 2005) olarak belirtilmiştir.

Özellikle Göreme Milli Parkı içerisindeki Babadağ civarında yüzeylenen ve pembe renkli pekleşmemiş ignimbiritler ve beyaz renkli sünger taşları ile karakterize edilen Zelve ignimbiritleri 7.7-7.5 my (Mues Schumacher ve Schumacher, 1996), 9-8.5 my 
(Le Pennec vd., 2005) dönemlerine tarihlendirilmiştir. Damsa vadisinin üst kesimlerinde yüzeylenen, pekleşmemiş şekilde bulunan Cemilköy ignimbiriti ise 8.4-7.6 my arasına tarihlendirilmiştir (Le Pennec vd., 2005). Cemilköy ignimbiriti içerisinde özellikle Damsa Çayı'nın batı yamaçlarında peribacası oluşumu görülmektedir (Sayın, 2008).

Çalışma alanını oluşturan ignimbirit ve tüf birimleri tüm çalışma alanının \%53.7'sini oluştururken, özellikle Damsa Çayı'nın her iki tarafından görülen Miyosen yaşlı konglomerakumtaşı-çamurtaşı ve kumtaşı-çamurtaşı ardalanmasından oluşan Tuzköy Formasyonu alanın \%26.5'lik kesimini oluşturur. Avanos civarında ve Damsa vadisi boyunca geniş bir yayılım gösteren alüvyon birimler ise alanın \%7'lik kesimini oluşturmaktadır. Kalan \%12.8'lik kesim ise kireçtaşı (\%4.1-Kışladağ Üyesi), bazalt
(\%3.7-Çataltepe, Damsa, Topuzdağı Bazaltları), dasit (\%1.7-Hoduldağ Domu), andezitten (\%1.2-Tekedağ Volkaniti) ve yamaç molozundan (\%2.1) oluşmaktadır.

\section{BULGULAR}

1/25.000 ölçekli topografya haritalar baz alınarak yapılan sayısallaştırma işlemine göre alanda 22 bin $(21,973)$ akarsu dizini sayısallaştırılmıştır. Strahler yöntemine göre numaralandırılan vadi kollarının \%53.3’ü 1. dizine aittir. Tüm havza içerisine dağılmış durumda olan 1. dizinler alanın güneydoğu kesiminde minimum yoğunluk değerine ulaşmaktadır. 1. dizinlerin ardından en fazla yoğunluk 2. (\%22.7) ve 3. (\%12.5) dizinlere aittir. 4.,5. ve 6. dizinler ise \%10.8'lik bir paya sahiptir (Şekil 4a-b). Tüm kolların Kızılırmak'a birleştiği noktada dizin sayısı 7’ye kadar

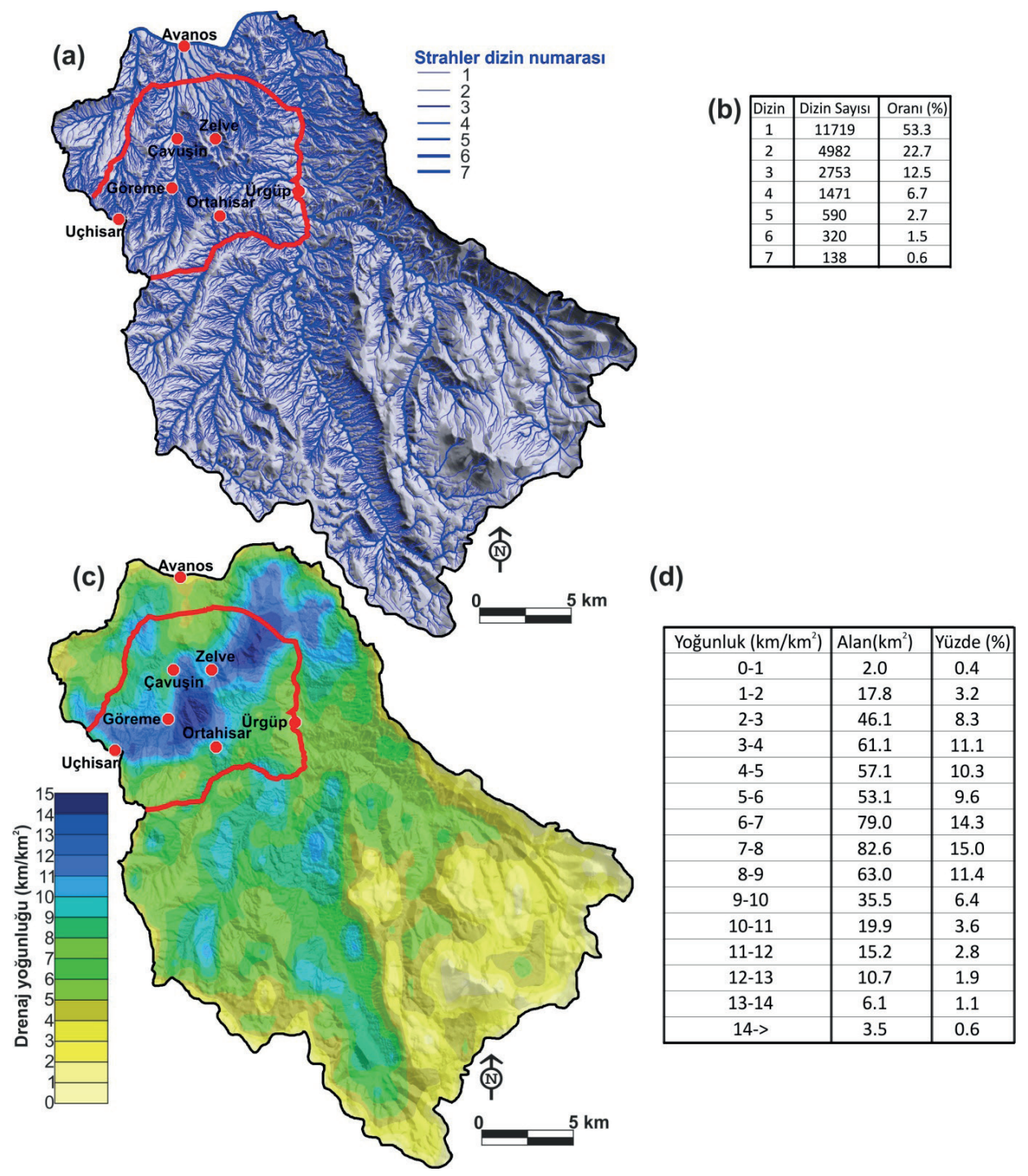

Şekil 4: (a,b) Çalışma alanı içerisindeki akarsuların Strahler dizin numarasına göre dağılışları (c) drenaj yoğunluğunun alansal dağılışı ve (d) yoğunlukların alan içerisinde kapladıkları oranları (Kırmızı çizgi Göreme Milli Parkı'nın sınırlarını göstermektedir).

Figure 4: $(a, b)$ Distribution of Strahler stream orders, (c) spatial distribution of drainage density and (d) percentage of density classes (red lines show boundary of the Göreme National Park). 
yükselmektedir. Ancak yedinci dizin akarsu kollarının sadece $\% 0.6$ 'llk kesimini meydana getirmektedir. Çalışma alanının $\% 53$ 'ünü oluşturan ignimbirit ve tüfler tüm akarsu dizinlerinin \%64'ünü, 1. ve 2.dizinlerin ise \% 66'sını içermektedir. Bu sonuçlar alanda birinci ve ikinci dizinin çok yaygın olmakla birlikte bunların büyük bölümünün ignimbirit ve tüfler üzerinde geliştiğini göstermektedir. Her iki dizinin ignimbirit ve tüfler üzerinde yaygın olması ise sel karakterli akarsuların bir sonucudur. Ayrıca alanın \%16'sını kaplayan Göreme Milli Parkı içerisinde tüm 1 ve 2. dizinlerin \%24'ü bulunmaktadır.
Alandaki ortalama drenaj yoğunluğu $6.4 \mathrm{~km} / \mathrm{km}^{2}$ iken maksimum yoğunluk $15.3 \mathrm{~km} / \mathrm{km}^{2}$ ye kadar çıkmaktadır. Yoğunluk alanın büyük bölümünde (tüm alanın \%83.6), özellikle Göreme Milli Parkı dışında alanlarda $9 \mathrm{~km} / \mathrm{km}^{2}$ 'den daha düşüktür (Şekil 4c-d). Güneydeki plato yüzeyleri üzerinde yoğunluk $3 \mathrm{~km} / \mathrm{km}^{2}$ den daha az iken, Damsa Çayı vadisinin üst yamaçlarında $10 \mathrm{~km} / \mathrm{km}^{2}$ yoğunluğa kadar yükselmektedir. En yüksek yoğunluk değerlerine $15.3 \mathrm{~km} / \mathrm{km}^{2}$ ile Göreme Milli Parkı sınırları içerisinde ulaşılmaktadır (Şekil 5a-b-c). Milli park sınırları içerisindeki Bozdağ'ın güneybatısında (Göreme,
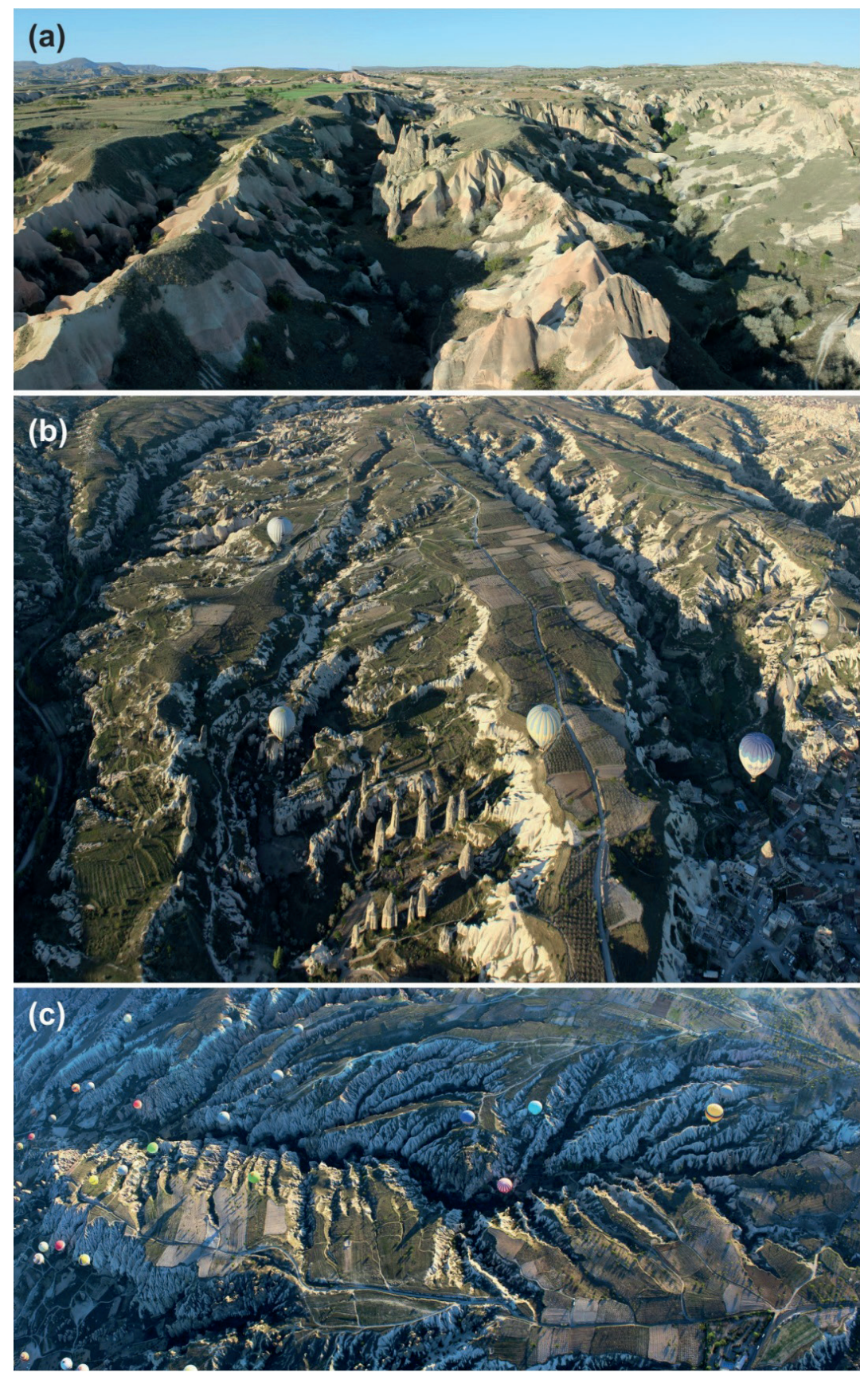

Şekil 5: Maksimum drenaj yoğunluğuna ulaşılan alanlara ait hava fotoları.

Figure 5: Air photography belong to maximum drainage density areas. 
Çavuşin, Ortahisar arasında) ve Zelve'nin kuzeydoğusunda en yüksek değerlere ulaşı1ır.

Litolojik birimlere göre ortalama drenaj yoğunluğu plato yüzeylerine karşl1ık gelen güneydoğu kesiminde bazaltta 3.5 $\mathrm{km} / \mathrm{km}^{2}$, dasitte $2.3 \mathrm{~km} / \mathrm{km}^{2}$, andezitte $2.2 \mathrm{~km} / \mathrm{km}^{2}$ ve kireçtaşında $4 \mathrm{~km} / \mathrm{km}^{2}$ ile özellikle dasit biriminin çevresindeki yamaç molozunda $3.3 \mathrm{~km} / \mathrm{km}^{2}$ 'dir. Bu birimler içerisinde minimum yoğunluk $0.05 \mathrm{~km} / \mathrm{km}^{2}$ ye (bazaltlarda) kadar düşmektedir (Tablo 1). Ortalama yoğunluk peribacalarının oluştuğu ignimbiritler $6.4 \mathrm{~km} / \mathrm{km}$, tüflerde $7.6 \mathrm{~km} / \mathrm{km}^{2}$ dir. Maksimum değerler açısından ise ignimbirit ve tüfler üzerinde yoğunluk 15.3 ve $15 \mathrm{~km} / \mathrm{km}^{2}$ yoğunluk değerleri ile litolojik birimler içerisindeki en yüksek değerlere ulaşır (Tablo 1).

Tablo 1: Litolojik birimlere göre maksimum, minimum ve ortalama drenaj yoğunlukları

Table 1: Change of maximum, minimum and mean drainage densities in lithological units.

\begin{tabular}{lccc}
\hline & \multicolumn{3}{c}{ Drenaj yoğunlukları (km/km²) } \\
\cline { 2 - 4 } Litolojik birim & Maksimum & Minimum & Ortalama \\
\hline İnimbirit & 15.3 & 0.5 & 6.4 \\
Tüf & 15 & 1.5 & 7.6 \\
Kumtaşı-Kiltaşı & 14.4 & 2.8 & 8.9 \\
Alüvyon & 12.9 & 2.9 & 7 \\
Konglomera-Kumtaşı-Kiltaşı & 12.2 & 2.1 & 6.8 \\
Kireçtaşı & 11.8 & 0.8 & 4 \\
Piroklastik kayaç & 10.5 & 1.3 & 6.8 \\
Yamaç molozu & 10.1 & 1.4 & 3.3 \\
Bazalt & 9 & 0.5 & 3.5 \\
Dasit & 4.2 & 0.9 & 2.3 \\
Andezit & 3.2 & 0.8 & 2.2 \\
\hline
\end{tabular}

Drenaj koşulları ile ilgili olarak hem akarsu dizin sayıları hem de akarsu yoğunluğunun alansal dağılış özelliklerine göre ignimbirit ve tüfler ile Göreme Milli Parkı içerisinde 1. ve 2. dizin akarsuların yaygın olarak gelişmektedir. Milli park sınırları içerisinde ise alandaki en yüksek akarsu yoğunluk değerlerine ulaşılmaktadır. Bu sonuçlar çalışma alanı içerisindeki peribacası oluşumlarının milli park içerisinde yaygın olmasında drenaj koşullarının belirleyici bir unsur olduğunu göstermektedir. Her iki birim içerisinde drenaj yoğunluğunun fazla olması üzerinde birçok faktör etkilidir: (1) birimlerin gözeneklilik oranlarının yüksek olması (Aydan ve Ulusay, 2003; Sayın, 2008) ve yoğun çatlak sistemleri ile kaplı olması (Topal ve Doyuran, 1997) birim içerisine sızan suların yapmış olduğu fiziksel ve kimyasal ayrışmayı kolaylaştırır. Özellikle soğuk mevsimde, birimlerin içerisine sızan suların neden olduğu donma-çözünme fiziksel parçalanmayı arttırmaktadır. (2) Birimlerin yoğun çatlak sistemleri ile kaplı olması ve iyi pekleşmemiş olmalarından dolayı sel karakterli sular tarafindan kolay bir şekilde işlenebilmelerini sağlamaktadır. (3) Birimler üzerinde bitki örtüsünün zayıf olması ise ayrışmış materyalin özellikle sağanak yağışlar sonucunda kolay bir şekilde taşınmasını sağlamaktadır.

\section{SONUÇ}

$\mathrm{Bu}$ çalışma kapsamında Göreme Milli Parkı içerisinde yer alan havzalar 1/25.000 ölçekli topografya haritaları üzerinden incelenmiş ve topografya haritalarından tespit edilen tüm vadi talvegleri sayısallaştırılmıştır. Yapılan haritalama çalışmalarına göre Göreme Milli Parkı içerisinde yer alan havzalar içerisinde 22 bin vadi segmenti tespit edilmiştir. Vadilerin Strahler dizin numaralarına göre tüm vadilerin $\% 76$ 'sı birinci ve ikinci dizin içerisinde yer almaktadır. Drenaj yoğunluğu haritasına göre maksimum akarsu yoğunluklarına Göreme Milli Parkı sınırları içerisinde, yüksek gözenekliliğe sahip, bitki örtüsünün zayıf olduğu, iyi pekleşmemiş ignimbirit ve tüflerde ulaşılmaktadır $\left(15.3 \mathrm{~km} / \mathrm{km}^{2}\right)$. Bu sonuçlar çalışma alanı içerisindeki peribacası oluşumlarının milli park içerisinde yaygın olmasında drenaj koşullarının belirleyici bir unsur olduğunu göstermektedir. Bununla birlikte milli park içerisindeki kırgıbayır topografyası özelliklerinin daha iyi ortaya konulması için yüksek çözünürlüklü (metre altı) modeller ile daha ayrıntılı çalışılması gerekmektedir. Ayrıca iklim özelliklerdeki farklılaşmanın kırgıbayır topografyası üzerinde nasıl bir etkisinin olduğunun ortaya konulabilmesi için mikro iklimsel çalışmalara ihtiyaç vardır.

\section{KAYNAKLAR}

Arık, A. (1981). Avanos (Nevşehir) yöresinin jeomorfolojisi. Jeomorfoloji Dergisi, 10, 139-154.

Altın, B, N. \& Toprak, V. (2007). Akarsu ağının morfolojik evrimi ile bölgesel tektonizma arasındaki ilişki Damsa ve Soğanlı havzaları örneği. 66. Jeoloji Kurultayı Bildiri Özleri Kitabı.

Atabey, E. (1989a). 1/100000 ölçekli açınsama nitelikli Türkiye jeoloji haritası serisi, Kayseri K33 paftası. MTA Genel Müdürlüğü, Jeoloji Etütleri Dairesi.

Atabey, E. (1989b). 1/100000 ölçekli açınsama nitelikli Türkiye jeoloji haritası serisi, Kayseri L33 paftası. MTA Genel Müdürlüğü, Jeoloji Etütleri Dairesi.

Aydan, Ö. \& Ulusay, R. (2003).Geotechnical and geoenvironmental characteristics of man-made underground structures in Cappadocia, Turkey. Engineering Geology, 6, 245-272.

Aydar, E., Çubukçu, H.E., Şen, E. \& Akın, L. (2012). Central Anatolian Plateau, Turkey: incision and paleoaltimetry recorded from volcanic rocks. Turkish Journal of Earth Sciences, 22, 739-746.

Baba, A., Kaya, A. \& Türk, N. (2005). Fairy chimneys of Cappadocia and their engineering properties. Journal of Applied Sciences, 5, 800-805. 
Bilgili, B. (2018). Kapadokya bölgesi Nevşehir yöresi kültürel varlıklarının bozulmalarına neden olan etmenler. Nevşehir Bilim ve Teknoloji Dergisi, 7(1), 60-74.

Chaput, E. (1947). Türkiye'de jeolojik ve jeomorfolojik tetkik seyahatleri. İst. Univ. Yay. 324, Ed. Fak. Coğ. Enst. Neş. 11, İstanbul.

Çiçek, İ. (1995). Türkiye>de kurak dönemin yayıllışı ve süresi (Thomthwaite metoduna göre). Türkiye Coğrafyası Ar. ve Uy. Mer. Dergisi, 4, 77-102.

Çiner, A., Sarıkaya, M.A. \& Aydar, E. (2013). Comments on "Monitoring soilerosion in Cappadocia region (Selime-AksarayTurkey)" by Yilmaz et al. (Environ Earth Sci 2012, 66, 75-81). Environ Earth Sci. 70, 1927-1931.

Çiner, A., Doğan, U., Yıldırım, C., Akçar, N., Ivy-Ochs, S., Alfimov, V., Kubik, P.W. \& Schlüchter, C. (2015). Quaternary uplift rates of the Central Anatolian Plateau, Turkey: insights from cosmogenic isochron-burial nuclide dating of the Kizılırmak Riverterraces. Quat. Sci. Rev. 107, 81-97.

Çiner, A. \& Aydar, E. (2019). A fascinating gift from volcanoes: The fairy fhimney sand underground cities of Cappadocia. In Land scapes and Landforms of Turkey (535-549). Springer, Cham.

Doğan, U. (2011). Climate-controlled river terrace formation in the Kizilirmak Valley, Cappadocia Section, Turkey: inferredfrom Ar$\mathrm{Ar}$ dating of Quaternary basalt sand terraces stratigraphy. Geomorphology, 126 (1-2), 66-81.

Doğan, U., Şenkul, Ç. \& Yeşilyurt, S. (2018). First paleo-fairy chimney findings in the Cappadocia Region, Turkey: a possible geomorphosite. Geoheritage https://doi.org/10.1007/s12371-018-0320-1.

Dönmez, M., Akçay, A. E. \& Türkecan, A. (2005). 1/100000 Ölçekli açınsama nitelikli Türkiye jeoloji haritası serisi, Kayseri K34 Paftası. MTA Genel Müdürlüğü, Jeoloji Etütleri Dairesi.

Emre, Ö. \& Güner, Y. (1985). Ürgüp-Avanos-Üçhisar (Nevşehir) arasının uygulamalı jeomorfolojisi. MTA Derleme Rapor no: 7677.

Emre, Ö. \& Güner, Y. (1988). Ürgüp yöresi peribacalarının morfojenezi. Jeomorfoloji Dergisi, 16, 23-30.

Erinç, S. (2000). Jeomorfoloji I. (6. Basım). Der Dayınları, İstanbul.

Erguler, Z. A. (2009). Field-based experimental determination of the weathering rates of the Cappadocian tuffs. Eng. Geol. 105 (3-4), 186-199.

Erşen, A. (2010). Avanos-Yemliha arasının jeomorfolojisi. Atatürk Üniversitesi Sosyal Bilimler Enstitüsü (Yüksek Lisans Tezi), Erzurum.

Garcia-Vallès, M., Topal, T. \& Vendrell-Saz, M. (2003). Lichenic growth as a factor of physical deteriorationor protection of Cappadocian monuments. Environ. Geol. 43 (7), 776-781.

Giovanni, L. (1971).The rock settlements, arts of Cappadocia.Nagel Publishers, Geneva.

Howard, A. D. (1994). Badlands. In Geomorphology of desertenvironments (213-242). Springer, Dordrecht.

Innocenti, F., Mazzuoli, R., Pasquare, G., Radicatidi Brozolo, F. \& Villari, L. (1975). The Neogenecalc-alkaline volcanism of Central Anatolia: geochronological data on Kayseri-Nijdearea.Geol. Mag. $112,349-360$.
Görüm, T., Gökçeoğlu, C., Zorlu, K., Tunusluoğlu, M. C. \& Nefeslioğlu, H. A. (2007). Kapadokya bölgesindeki aşınım birimlerinin morfometrik özellikleri. Kapadokya Yöresinin Jeolojisi Seтроzуuтu Bildiriler Kitabı, 53-70.

Güngör, Ş. (2016). Koruma statülerinin koruma-kullanma dengesine etkisi: Zelve Açık Hava Müzesi (Nevşehir/Avanos). Gaziantep University Journal of Social Sciences 15(1),205-223.

Koçyiğit. A. \& Doğan, U. (2016). Strike-slip neotectonic regime and related structures in the Cappadocia region: a case study in the Salanda basin, Central Anatolia, Turkey. Turk J Earth Sci. 25, 393 417.

Kopar, İ. (2010). Akdağ ve Topuz Dağ1 (Nevşehir) civarındaki peribacaları gövdesinde oluşan oksidasyon kabuğu ve morfojenetik önemi. Türk Coğrafya Dergisi, 54, 53-68.

Le Pennec, J.-L., Temel, A., Froger, J.-L., Şen, S., Gourgaud, A. \& Boudier, J.-L. (2005). Stratigraphy and age of the Cappadocia ignimbrites, Turkey: reconciling field constraints with paleontologic, radiochronologic, geochemical and paleomagnetic data. Journal of Volcanology and Geothermal Research, 141, 45- 64.

Mues-Schumacher, U. \& Schumacher, R. (1996). Problems of stratigraphic correlation and new K-Ar data for ignimbrites from Cappadocia, central Turkey. International Geology Review, 38, 737-746.

Nadal-Romero, E.,Martínez-Murillo, J. F., Vanmaercke, M. \& Poesen, J. (2011). Scale-dependency of sedimentyield from badland areas in Mediterranean environments. Progress in Physical Geography, 35(3), 297-332.

Ozaner, S. \& Atiker, M. (2006). Kapadokya Yöresi'nin jeomorfolojik oluşum ve gelişimi ile ekoturizm ve jeopark potansiyeli, Kapadokya Yöresi'nin bilimsel eğitim amaçl kullanımı projesi-II, Proje No: TÜBİTAK YDABAG 105Y017, Ankara.

Özdemir, H. (2006). Taşkın çalışmaları açısından topografik haritalardan ve DEM'den üretilmiş akarsu morfometrik özelliklerin karşılaştırılmas1. 1. Uzaktan Algılama-CBS Çalıştay ve Paneli-2006 (UZAL-CBS-2006).

Özdemir, H. (2011). Havza morfometrisi ve taşkınlar. Fiziki Coğrafya Araştırmalarl; Sistematik ve Bölgesel, Türk Coğrafya Kurumu Yayınlart, 5, 507-526.

Öztürk, M. Z., Çetinkaya, G. \& Aydın, S. (2017). Köppen-Geiger iklim sınıflandırmasına göre Türkiye'nin iklim tipleri. Coğrafya Dergisi, $35,17-27$.

Pasquarè, G. (1968). Geology of the Cenozoic volcanic area of Central Anatolia. Atti Accademia Nazionale dei Lincei 9, 55-204.

Phillips, C. P. (1998). The badlands of Italy: a vanishing landscape. Applied geography, 18(3), 243-257.

Polat, S. \& Güney, Y. (2013). Damsa çayı vadisinde (Cemil-Şahinefendi köyleri arası) kaya düşmesi olayı ile peribacası oluşumu arasındaki ilişki. Marmara Coğrafya Dergisi, 28,18-46.

Sarikaya, M.A., Çiner, A. \& Zreda, M. (2015). Fairy chimney erosion rates on Cappadocia ignimbrites, Turkey: Insights from cosmogenic nuclides. Geomorphology, 234, 182-191. 
Sayın, M. N. (2018). Fairy chimney development in cappadocian ignimbrites (Central Anatolia, Turkey). Ortadoğu Teknik Üniversitesi (Doktora Tezi), Ankara.

Strahler, A. N. (1957). Quantitative analysis of watershed geomorphology. Transactions, American Geophysical Union 38, 913-920.

Sür, Ö. (1966). Nevşehir ve Ürgüp çevresinde jeomorfoloji araştırmaları. Coğrafya Araştırma Dergisi, 1, 179-200.

Şener, M. F. (2015). Kapadokya jeotermal provensinin jeotermal kaynak potansiyeli. Niğde Üniversitesi, Fen Bilimleri Enstitüsü (Doktora Tezi), Niğde.

Şener, M.F., Şener, M. \& Uysal, T. (2017). The evolution of the Cappadocia geothermal province, Anatolia (Turkey): geochemical and geochronological evidence. Hydrogeology Journal, 8, 23232345

Tanrıkulu, İ. (2016). Türkiye'de peribacalarının (badlands topoğrafyası) coğrafi dă̆ılımı ve peribacalarının oluşum ve gelişimini etkileyen doğal faktörler. Harran Üniversitesi, Sosyal Bilimler Enstitüsü (Yüksek Lisans Tezi), Şanlıurfa.

Temel, A. (1992). Kapadokya eksplosif volkanizmasının: petrolojik ve jeokimyasal özellikleri. Hacettepe Üniversitesi (Doktora Tezi), Ankara.

Topal, T. (1995). Formation and deterioration of fairychimneys of the Kavak tuff in Ürgüp-Göreme area (Nevşehir-Turkey). Orta Doğu Teknik Üniversitesi (Doktora Tezi), Ankara.
Topal, T. \& Doyuran, V. (1997). Engineering geological properties and durability assessment of the Cappadocian tuff. Engineering Geology 47, 175-187.

Topal, T. \& Doyuran, V. (1998). Analyses of deterioration of the Cappadocian tuff, Turkey. Environmental Geology, 34(1), 5-20.

Tromp, S.W. (1942). Niğde-İncesu, Kızılırmak ve Tuzgölü arasında bulunan mintıkaların jeolojik etüdü. MTA Rapor no: 1450.

Tucker, G. E., Catani, F., Rinaldo, A. \& Bras, R. L. (2001). Statistical analysis of drainage density from digital terrain data. Geomorphology, 36(3-4), 187-202.

Turoğlu, H. (1997). İyidere havzasının hidrografik özelliklerine sayısal yaklaşım. Türk Coğrafya Dergisi, 32, 355-364.

Türkeş, M. (2005). Orta Kızılırmak Bölümü güney kesiminin (Kapadokya Yöresi) iklimi ve çölleşmeden etkilenebilirliği. Ege Coğrafya Dergisi, 14(1-2), 73-97.

Utlu, M. \& Özdemir, H. (2018). Havza morfometrik özelliklerinin taşkın üretmedeki rolü Biga Çayı havzası örneği. Coğrafya Dergisi, (36), 49-62.

Yalçınlar, İ. (1969). Strüktüral jeomorfoloji, Cilt II. İstanbul Üniversitesi Yayınları No: 878, İstanbul.

Y1lmaz, H.M., Yakar, M., Mutluoglu, O., Kavurmaci, M. M. \& Yurt, K. (2012). Monitoring of soil erosion in Cappadocia region (SelimeAksaray-Turkey). Environ Earth Sci, 66, 75-81. 